\title{
Experimental Analysis of Pressure Drop in Hydrophobic small pipes
}

\author{
MIKE KNIGHTS ${ }^{1}$, Roy Donald ${ }^{1}$, Diego Galletta ${ }^{1}$, Kul Pun ${ }^{1}$, and F A Hamad ${ }^{1}$ \\ ${ }^{1}$ Teesside University Middlesbrough
}

May 5, 2020

\begin{abstract}
In this paper, experimental results are reported to quantify the effect of hydrophobic coating LT-8 on frictional drag of water flow in pipes of $450 \mathrm{~mm}$ length. Five pipes of 1, 2, 3, 4 and $5 \mathrm{~mm}$ inner diameter were tested. The results from 1,2 and $3 \mathrm{~mm}$ diameter pipes demonstrated an average frictional drag reduction of $9 \%, 11.5 \%$ and $3 \%$, respectively, while the results from $4 \mathrm{~mm}$ and $5 \mathrm{~mm}$ pipes showed an increase in frictional drag of $12 \%$ and $10 \%$, respectively. The $2 \mathrm{~mm}$ and $4 \mathrm{~mm}$ pipes were also tested with a half application of hydrophobic coating. The half coated $2 \mathrm{~mm}$ pipe showed decrease in drag while $4 \mathrm{~mm}$ pipe showed increase in drag. The results indicate a relationship between drag reduction/ increase withnthe percentage of coated surface. The main conclusions are, the flow changed from laminar state to the liquid-air wetting surface condition (Cassie-Baxter wetting state) at the pipe surface and then destabilized by the turbulent boundary layer and entered the liquid wetting surface (Wenzel wetting state) will be appeared. This transition lead to a reduction in friction drag for laminar flow condition and increase in drag for turbulent flow condition.
\end{abstract}

\section{Hosted file}

ManuscriptHTARm.docx available at https://authorea.com/users/293108/articles/421012experimental-analysis-of-pressure-drop-in-hydrophobic-small-pipes 